\title{
Understanding Gender Inclusion Using Environment and Gender Index: A Secondary Analysis Positioning India
}

\author{
Nivedita Roy*, Atasi Choudhury \\ OPJS University, Rajasthan, India \\ Email: *roynivedita17@gmail.com, atasichoudhury@gmail.com
}

How to cite this paper: Roy, N., \& Choudhury, A. (2022). Understanding Gender Inclusion Using Environment and Gender Index: A Secondary Analysis Positioning India. Open Journal of Social Sciences, 10, 59-71.

https://doi.org/10.4236/jss.2022.102003

Received: November 18, 2021

Accepted: February 8, 2022

Published: February 11, 2022

Copyright $\odot 2022$ by author(s) and Scientific Research Publishing Inc. This work is licensed under the Creative Commons Attribution International License (CC BY 4.0).

http://creativecommons.org/licenses/by/4.0/

\begin{abstract}
Gender discrimination is already one of the major factors why India is still on the list of the 3rd World Countries, but when it comes to gender inclusion in the environmental arena, this umbrella concept is relatively unheard of by our countrymen. The main objective was to assess gender equality for the environment through calculating Environment and Gender Index on a country level, India, in this case. 22 states out of 29 were considered for calculation. Linear Regression is executed through SPSS, and simple graphs and tables are prepared through MS-EXCEL for analysis. India portrays good governance, reporting activities well to the $\mathrm{UN}$, but the performance is comparatively weak in terms of basic livelihood and gender equality.
\end{abstract}

\section{Keywords}

Environment, Gender, Livelihood, Rights, Participation, Development, Conservation

\section{Background of the Study}

Gender issues have been a part of international as well as academic debates past two decades, specifically in terms of Gender Index issues as these indexes try to mathematically compute different composite indicators: tools combining different pieces of information together into indices (Agarwal, 1992; Central Statistical Office, 2012; FAO, 2005). Measuring and collecting gender data in the realm of environment and sustainable development would significantly bolster monitoring and evaluation efforts, promote efficiency and effectiveness and contribute to enhanced decision-making and performance, and accountability (Hayson, 2014). Apart from MDGs and CEDAW, various indexes on gender which are at the fo- 
refront of international debates are Global Gender Gap Index, Gender Inequality Index, Gender Empowerment Measure, Gender Equality Index but the indicators underlying are currently not included comprehensively in environmental monitoring and evaluation mechanisms (Helliwell et al., 2014; Institute of Applied Manpower Research, 2012; Irish Aid, 2006). Simultaneously, environmental indicators are not included or featured prominently in some of the primary global indexes (IUCN, 2013a; IUCN, 2013b; Kakashel, 2012). There have been recent advancements in the generation of sex aggregated statistics in the social, economic, and political spheres, but environmental data is rarely sex-disaggregated at the national or global level (Ministry of Women and Child Development, 2009). The Environment and Gender Index is a groundbreaking new measure that, for the first time in history, provides quantitative data on how nations are incorporating global gender and environmental mandates into their national policy and planning (National Institute of Public Cooperation and Child Development, 2010; Phillips, 2014).

The Environment and Gender Index (EGI), launched in 1913 by the global gender office of the International Union for conservation of nature (IUCN), has endeavored to make the targets, plan, and gender commitment in climate change policy by governments both quantifiable and measurable (IUCN, 2013b). The EGI highlights the importance of giving more weight to accountability and the critical need to mainstream gender policy in global climate change in ways that can be evaluated and monitored. It is intended as a tool that is useful for government and civil societies and researchers to track how governments fare in meeting gender commitments.

The EGI ranks 72 countries using 27 indicators that have been grouped into six environment and gender categories: livelihood, ecosystem, gender-based rights and participation, governance, gender-based education and assets, and country-reported activities. In terms of top country performances, Iceland ranks first with scoring the highest in most categories like lower performance on women in COP delegations, female managers, senior officials, legislators, and country reporting on CBD and CEDAW. Poland ranks the highest worldwide in the ecosystem category and the lowest in the livelihood category in OECD countries. The USA has the highest performance on percentage of women without anemia and lower performance equal to Greece and Bangladesh on women in policy-making positions. India ranks $47^{\text {th }}$ in EGI score performing the highest in inclusion of gender in UNFCCC, and UNCCD reports.

A very important international mandate working towards gender equality and empowerment of women is the Sustainable Development Goals (Rao \& Dr 2012; Rustagi, 2004). The fifth goal is decided to promote gender equality and the empowerment of women. However, when we look at the other goals, it is to be noted that none of the goals can be achieved without an improved situation for the women of the world and inclusion of gender considerations. This is where the main research question for this paper lies: what are the various possible cri- 
teria for gender inclusion to improve and enhance women empowerment in the world. Poverty and hunger can be eradicated, but only if women's voices are fully involved in decisions on agriculture and biodiversity, education, policy-making, health and economics. Efforts of Development have been hindered by scarcity of data in all aspects women empowerment measures and thus, Environment and Gender Index (EGI) is an effective solution to it (Young, 2013).

\section{Objectives}

The overall objective of the paper is to assess Environment and Gender Index with the following specific objectives:

1) Calculating state-level EGI for India and assessing their performance.

2) Exploring various factors affecting EGI of both lower middle-income groups of countries in the world and states of India.

\section{Conceptual Framework}

The EGI as introduced by IUCN, has a framework of 6 categories and 27 indicators. [8] The gist of it is presented as under:

Category 1: Livelihood: This category provides the baseline indication of a country's abilities to meet the fundamental needs of its population. Little sex-disaggregated data is available for this issue, but IUCN could include a longitudinal assessment of women's health as proxied by the percentage of women without anemia. There are six indicators under it are as follows:

1) Less Poverty; 2) Food Adequacy; 3) Fewer Women with Anemia; 4) Less solid fuel use; 5) Improved water; 6) Improved Sanitation.

Category 2: Ecosystem: This category focuses on presenting the specific factors related to environmental preservation, sustainability, and resource use. No sex-disaggregated data is available for this category:

7) Biodiversity preservation; 8) Critical habitat protection; 9) Higher quality forests.

Category 3: Gender-Based Rights and Participation: This category explicitly addresses a country's commitment to gender equality and the ability of women to engage in leadership and decision-making roles.

10) Equal Legal Rights; 11) CEDAW Ratification; 12) Women in COP Delegations; 13) Women managers, legislators, and senior officials; 14) Women in Policy-Making positions.

Category 4: Governance: This category assesses the effectiveness of a country's fundamental institutional capacities as well as the ability of its women to participate freely in the political process:

15) Civil Liberties; 16) Political stability; 17) Property Rights.

Category 5: Gender-Based Education and Assets: This category focuses on equal access for women to primary education and resources. Access to these essential resources provides women with the tools, skills, and preparation to effectively engage in environmental decision making and resource use and access: 
18) Access to agricultural land; 19) Access to property; 20) Access to credit; 21) Women with bank account; 22) Female post-primary education; 23) Female Literacy.

Category 6: Country Reported Activities: EGI team assesses a country's inclusion of gender in Conference of Parties (COPs) reports and a country's inclusion of environmental sustainability in CEDAW reports.

24) Inclusion of gender in UNFCCC reports; 25) Inclusion of gender in UNCCD reports; 26) Inclusion of gender in CBD reports; 27) Inclusion of sustainable developments topics in CEDAW reports.

\section{Data}

Calculating EGI for each state for a country-level analysis itself is a huge task. The indicators are dynamic in nature considering the Environment and Gender Index framework and are to be collected from various data sources. Thus a few indicators are not taken into consideration due to both unfeasibility and unavailability of data. The first step was to normalize the data for each variable under each indicator. The values are normalized on the basis of:

(Observed Value - Minimum Value)/(Maximum Value - Minimum Value)

Thereafter, the indicators under each category are averaged, and thus, a mean value for each category is figured to calculate each category indexes. These categories are then weighted as follows:

Livelihood: 20\%, Ecosystem: 10\%, Gendered Rights + Participation: 20\%, Governance: 20\%, Gendered Education and Asset. 20\%, Country Reported Activities: $10 \%$.

The remaining two EGI categories: Ecosystem and Country-Reported Activities received lower weighting. Even though the Ecosystem category is very important to the EGI index, the complete lack of sex-disaggregated data for women's access, influence and decision making roles in biodiversity, sustainability, forestry, agriculture and fisheries meant that the indicators used were quite distant "proxies" for what the EGI ideally intends to measure. EGI is calculated as follows:

$\mathrm{EGI}=1 / 5$ * $\mathrm{LI}+1 / 10$ * $\mathrm{EI}+1 / 5 * \mathrm{GI}+1 / 5$ * GBRPI $+1 / 5$ * SRAI $+1 / 10$ * GBEAI

\section{Methods}

The indicators with the variables used for these indicators to measure EGI state wise in India are as follows (Table 1).

The other indicators like Gross Domestic Product, Gross National Happiness, Crude Birth Rate, Incidence of sexual violence, Gender Development Index, Gender Empowerment Index, Environmental Performance Index are taken from multiple data sources (sources given in the appendix). These associations are made by using Simple linear regression method using curve estimation fit in SPSS. 
Table 1. Indicators of EGI taken for calculating EGI for states of India.

\begin{tabular}{|c|c|c|}
\hline Overall Dimension & Variable taken for each indicator & Data Sources \\
\hline Livelihood & $\begin{array}{l}\text { 1) Less Poverty: Percentage of population below } \\
\text { poverty line in each state } \\
\text { 2) Food Adequacy: Per capita calorie intake in each } \\
\text { state (kcal/person) } \\
\text { 3) Fewer Women with Anemia: Percentage of women } \\
\text { without anemia in each state } \\
\text { 4) Less solid fuel use: Percentage of household using } \\
\text { solid fuel for cooking in each state } \\
\text { 5) Improved water: Percentage of household with } \\
\text { improved sector of drinking water in each state } \\
\text { 6) Improved Sanitation: Percentage of household } \\
\text { with toilet facility in each state }\end{array}$ & $\begin{array}{l}\text { The data source for these indicators } \\
\text { for state level calculation of EGI is } \\
\text { International Institute for Population } \\
\text { Sciences, National Family Health } \\
\text { Survey Report, 2015-2016. }\end{array}$ \\
\hline Ecosystem & $\begin{array}{l}\text { 7) Biodiversity preservation: Number of wildlife } \\
\text { sanctuaries in each state } \\
\text { 8) Critical habitat protection: Percentage of Reserved } \\
\text { forest of the total geographical area in each state } \\
\text { 9) Higher quality forests: Forest Growing Stock } \\
\text { volume (m cum) for each state }\end{array}$ & $\begin{array}{l}\text { The data source for these indicators } \\
\text { for state level calculation of EGI is } \\
\text { Ministry of Environment and Forests, } \\
\text { Annual Report 2015-2016, } \\
\text { b. data.gov.in }\end{array}$ \\
\hline $\begin{array}{c}\text { Gender-Based } \\
\text { Rights + Participation }\end{array}$ & $\begin{array}{l}\text { 10) Equal legal rights: Percentage of women who alone } \\
\text { or jointly with husbands decide how their husband's } \\
\text { earnings are used } \\
\text { 11) CEDAW Ratification: Not feasible for each state } \\
\text { 12) Women in COP Delegations: Not feasible for each } \\
\text { state } \\
\text { 13) Women managers, legislators and senior officials: } \\
\text { Women Entrepreneurship Profile } \\
\text { 14) Women in Policy-Making positions: Percentage } \\
\text { of Women in District Panchayat, Percentage of } \\
\text { women in state assembly. }\end{array}$ & $\begin{array}{l}\text { The data source for number } 9 \text { is IIPS, } \\
\text { NFHS } 2015-16 \text { p. } 459 \text {. } \\
\text { Women entrepreneurship profile taken } \\
\text { from data.gov.in. } \\
\text { Two variables of women in policy } \\
\text { making positions are taken from Rural } \\
\text { Development Statistics Report } \\
\text { 2016-2017. }\end{array}$ \\
\hline
\end{tabular}

15) Civil Liberties: Percentage of total women voter's turnout state wise

Governance 16)Political stability: could not find reliable data on terrorism or political instability

17) Property Rights: Percentage of women with Agricultural Landholdings
The data source for civil liberties is data.gov.in and that for property rights is NFHS 2015-16.
18) Access to agricultural land: Percentage of female agricultural workers

19) Access to property: Access to property any other than land, no reliable data could be found.

20) Access to credit: Percentage of women who have

Gender-Based

Education + Asset taken a loan from a microcredit program.

21) Women with bank accounts: Percentage of women who has savings account they themselves use.

22) Female post-primary education: Per 1000 distribution of women who has attained higher level of education

23) Female Literacy: Female Literacy rate
The data source is IIPS, NFHS 2015-2016.

However, for state level calculation, this category itself is not feasible unless we use state reported activities, which, again needs enough thinking as to which variable to take.

The EGI indicators are: 


\begin{tabular}{lll}
\hline & 24) Number of Government Schemes and \\
& Development Programs in each state. \\
& The indicator for state level calculation chosen is a \\
number of government schemes and development & \\
programs in each state, as the idea of state & Data vault of IFMR Research, \\
gevernment Schemes and & Centre for Micro Finance \\
& or other institutions on environment and/or \\
gender is non-existent. & \\
& This indicator could act as a category on its own \\
& instead of country reported activities. & \\
\hline
\end{tabular}

\section{Results}

With 24 indicators used to calculate the EGI and its categories for 22 states (Table 2), Kerala and Tamil Nadu tops the list, Tripura and Manipur scores the lowest. Each of these 22 states with their EGI scores is compared with the same score by other countries matching a state (Table 2 and Table 3). The EGI score of Kerala and Tamil Nadu is matched with Dominican Republic, and the EGI score of Tripura and Manipur is matched with EGI score of Mauritania and Syria, respectively. An interval score of 5 is maintained in the EGI score. Accordingly, 3 more counties are selected for comparison purposes-Chhattisgarh, Haryana, Rajasthan, which are matched with Saudi Arabia and Cameroon. Being high or low in EGI score, the Gender base rights and participation are always low, whereas on the contrary, the governance indexes is high consistently (Figures 1-4).

In terms of the third objective different exploratory factors from different dimensions like Gross Domestic Product per capita (for country level), Net state Domestic Product per capita (for state-level), Crude Birth Rate, Incidence of Sexual Violence are considered that could affect EGI. In terms of LMI country level, Per Capita Gross Domestic Product shows a positive relation with EGI with $r$ square value of 0.373 . This means income does affect the gender and environment association. When tried to explore the possibility of any association with Gross National Happiness, the r square value is 0.157 (Figure 5 and Figure 6).

Again, there is a fine inverse relation between Crude Birth Rate and EGI of these countries with $r$ square value of 0.535 (Figure 7). The percentage of women suffering from sexual violence does not affect the EGI of these LMI countries (Figure 8).

In terms of states of India and their EGI performance, income seems to be not a factor associated with gender equality for the environment (Figure 9). The Per Capita Net State Domestic Product shows a weak relationship with r square value of 0.0003. Similarly, the relationship between Crude Birth Rate and EGI is evidently weak by an $r$ square value of 0.0007 (Figure 10).

However, there is a strong relationship between the percentage of women 


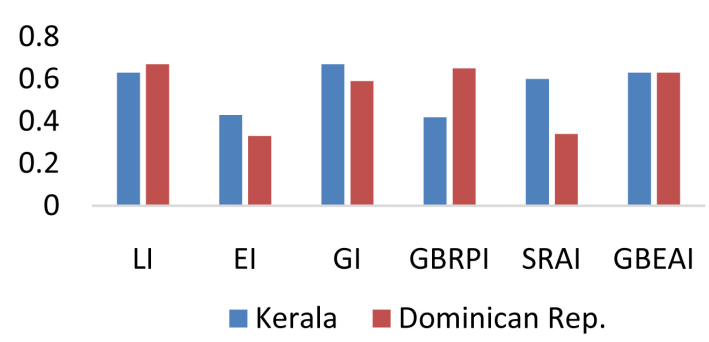

Figure 1. Comparison between Kerala and Dominican Rep.

Table 2. Calculated LI, EI, GI, GBRPI, SRAI, GBEAI, EGI for each state.

\begin{tabular}{|c|c|c|c|c|c|c|c|}
\hline States & LI & EI & GI & GBPRI & SRAI & GBEAI & EGI \\
\hline Andhra Pradesh & 0.47 & 0.64 & 0.81 & 0.35 & 0.37 & 0.55 & 0.52 \\
\hline Arunachal Pradesh & 0.61 & 0.25 & 0.53 & 0.32 & 0.19 & 0.29 & 0.38 \\
\hline Assam & 0.57 & 0.45 & 0.52 & 0.38 & 0.07 & 0.33 & 0.39 \\
\hline Bihar & 0.54 & 0.22 & 0.51 & 0.52 & 0.96 & 0.26 & 0.56 \\
\hline Chhattisgarh & 0.54 & 0.46 & 0.48 & 0.38 & 0.50 & 0.23 & 0.45 \\
\hline Goa & 0.45 & 0.09 & 0.51 & 0.36 & 0.23 & 0.69 & 0.39 \\
\hline Gujarat & 0.38 & 0.52 & 0.44 & 0.42 & 0.66 & 0.42 & 0.47 \\
\hline Haryana & 0.60 & 0.10 & 0.46 & 0.36 & 0.36 & 0.30 & 0.40 \\
\hline Himachal Pradesh & 0.52 & 0.35 & 0.42 & 0.38 & 0.49 & 0.47 & 0.44 \\
\hline Jharkhand & 0.35 & 0.29 & 0.48 & 0.52 & 0.26 & 0.31 & 0.38 \\
\hline Karnataka & 0.55 & 0.53 & 0.58 & 0.41 & 0.26 & 0.48 & 0.46 \\
\hline Kerala & 0.63 & 0.43 & 0.67 & 0.42 & 0.60 & 0.63 & 0.57 \\
\hline Madhya Pradesh & 0.41 & 0.57 & 0.42 & 0.43 & 0.73 & 0.26 & 0.48 \\
\hline Maharashtra & 0.57 & 0.77 & 0.62 & 0.34 & 0.30 & 0.41 & 0.48 \\
\hline Manipur & 0.47 & 0.10 & 0.53 & 0.46 & 0.20 & 0.31 & 0.37 \\
\hline Odisha & 0.54 & 0.50 & 0.50 & 0.34 & 0.76 & 0.36 & 0.51 \\
\hline Punjab & 0.72 & 0.14 & 0.45 & 0.32 & 0.30 & 0.39 & 0.41 \\
\hline Rajasthan & 0.54 & 0.45 & 0.41 & 0.41 & 0.50 & 0.23 & 0.44 \\
\hline Tamil Nadu & 0.41 & 0.44 & 0.67 & 0.60 & 0.69 & 0.51 & 0.57 \\
\hline Tripura & 0.50 & 0.37 & 0.55 & 0.28 & 0.04 & 0.38 & 0.35 \\
\hline Uttar Pradesh & 0.55 & 0.44 & 0.53 & 0.43 & 0.30 & 0.32 & 0.44 \\
\hline \multirow[t]{2}{*}{ West Bengal } & 0.57 & 0.30 & 0.57 & 0.34 & 0.30 & 0.33 & 0.42 \\
\hline & & & & & & INDIA - & 0.45 \\
\hline
\end{tabular}

Note: $\mathrm{LI}=$ Livelihood Index, EI = Ecosystem Index, GI = Governance Index, GBRPI = Gender Based Rights and Participation Index, SRAI = State Reported Activities Index, GBEAI = Gender Based Education and Asset Index, EGI = Environment and Gender Index. India's EGI score is 0.45 here, whereas IUCN has calculated the score as 0.49 . The gap is due to not taking into consideration all 29 states of India. 


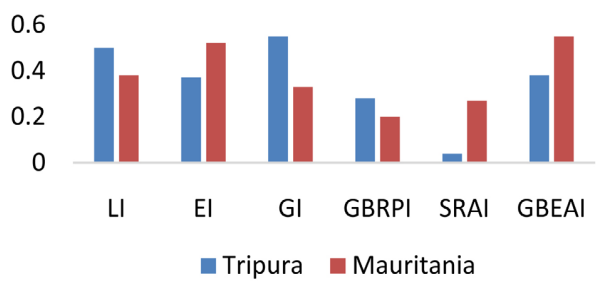

Figure 2. Comparison between Tripura and Mauritania.

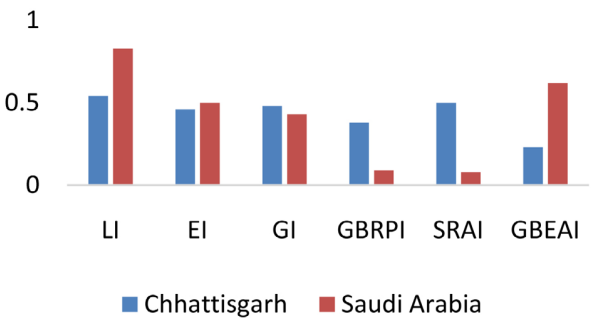

Figure 3. Comparison between Chhattisgarh and Saudi Arabia.

Table 3. Ranked EGI scores of 22 Indian states compared other countries of same EGI scores.

\begin{tabular}{|c|c|c|c|}
\hline States & AGE & RANK & Comparable Countries \\
\hline Andhra Pradesh & 0.52 & 4 & Sri Lanka \\
\hline Arunachal Pradesh & 0.38 & 19.5 & Pakistan \\
\hline Assam & 0.39 & 17.5 & Congo \\
\hline Bihar & 0.56 & 3 & Indonesia \\
\hline Chhattisgarh & 0.45 & 10 & Saudi Arabia \\
\hline Goa & 0.39 & 17.5 & Congo \\
\hline Gujarat & 0.47 & 8 & Egypt \\
\hline Haryana & 0.40 & 16 & Cameroon \\
\hline Himachal Pradesh & 0.44 & 12 & Algeria \\
\hline Jharkhand & 0.38 & 19.5 & Pakistan \\
\hline Karnataka & 0.46 & 9 & Liberia \\
\hline Kerala & 0.57 & 1.5 & Dominican Republic \\
\hline Madhya Pradesh & 0.48 & 6.5 & Burkina Faso \\
\hline Maharashtra & 0.48 & 6.5 & Burkina Faso \\
\hline Manipur & 0.37 & 21 & Syria \\
\hline Odisha & 0.51 & 5 & Uzbekistan \\
\hline Punjab & 0.41 & 15 & Uganda \\
\hline Rajasthan & 0.44 & 12 & Madagascar \\
\hline Tamil Nadu & 0.57 & 1.5 & Dominican Republic \\
\hline Tripura & 0.35 & 22 & Mauritania \\
\hline Uttar Pradesh & 0.44 & 12 & Madagascar \\
\hline West Bengal & 0.42 & 14 & Gambia \\
\hline
\end{tabular}




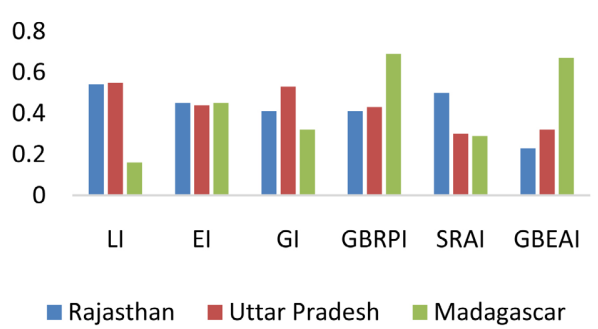

Figure 4. Comparison between Rajasthan, Uttar Pradesh and Madagascar.

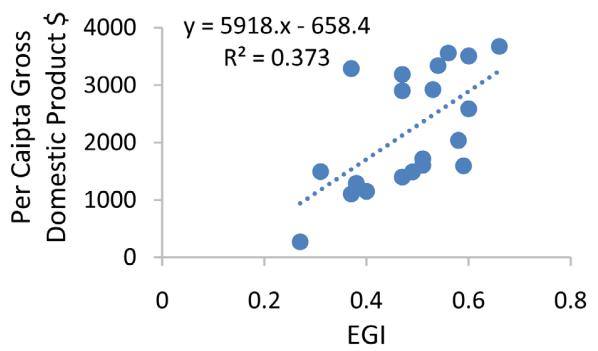

Figure 5. Regression between GDDPPC and EGI (countries).

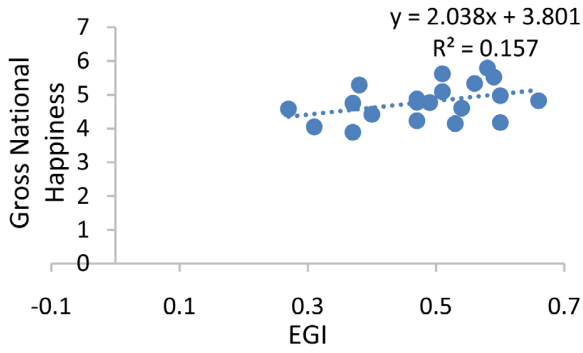

Figure 6. Regression between GNH and EGI (countries).

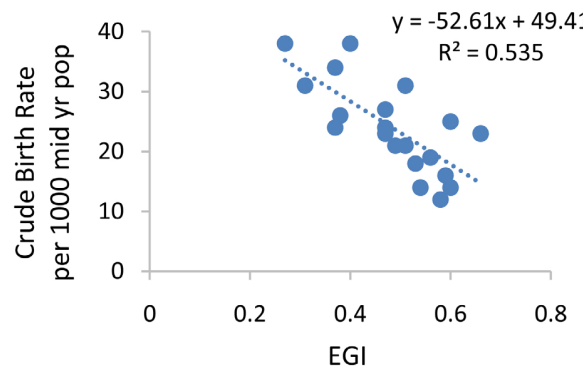

Figure 7. Regression between CBR and EGI for countries.

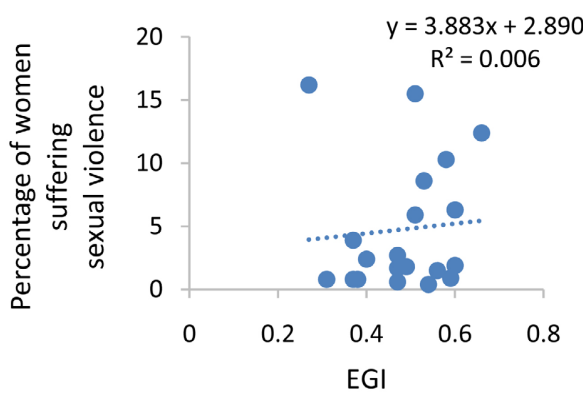

Figure 8. Regression between Sexual Violence and EGI for countries. 


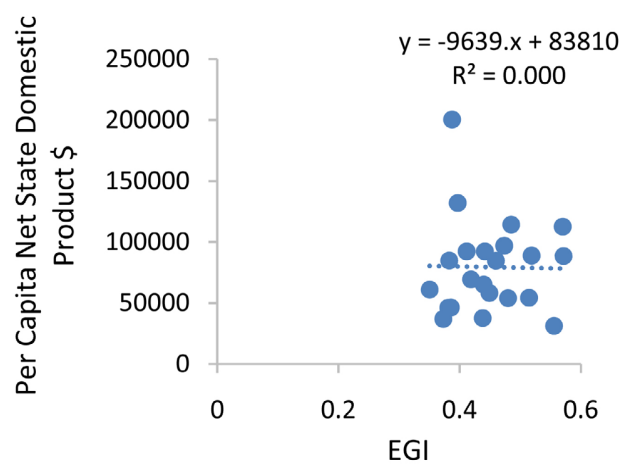

Figure 9. Regression between NSDPPC and EGI for Indian states.

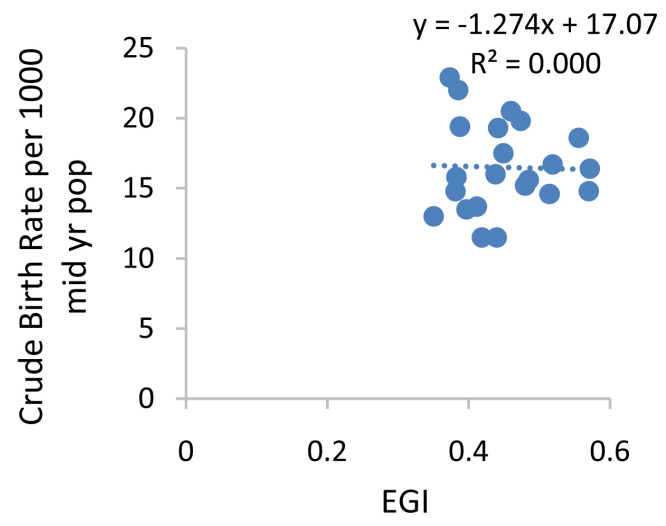

Figure 10. Regression between CBR and EGI for Indian states.

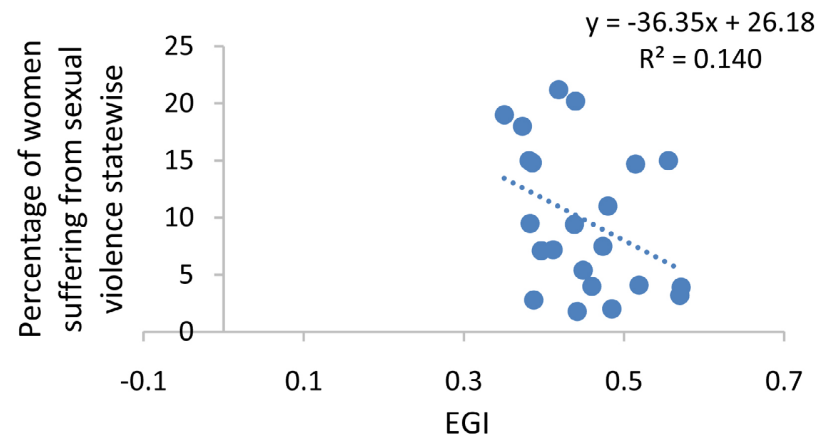

Figure 11. Regression between incidence of sexual violence and EGI for Indian states.

suffering from sexual violence and EGI of the states with $\mathrm{r}$ square values of 0.129 and 0.140 , respectively (Figure 11). When it comes to associating the EGI of the states of India with other indexes relating to gender and environment, though separately, comparatively less association is seen except the relation between Environmental Performance Index and Environment and Gender Index defined by an $r$ square value of 0.1932 .

\section{Limitations}

The study had a few limitations. All 29 states of India could not be taken due to the unavailability of data of a few variables under the indicators. EGI, consisting 
of 6 categories and 26 indicators, all 26 indicators are not taken into account due to infeasibility of data for few indicators (Note: Table 1). The country-reported activities as a category in itself are not considered; instead, Government Schemes and Development Programmes are contributed as an indicator. Lack of sex-disaggregated data for many indicators could not accurately portray gender equality status in the environmental arena.

\section{Findings with Analysis}

While comparing the state scoring highest in EGI (Kerala), with a country with the same EGI (Dominican Republic), we say that both run neck to neck only Dominican Republic is less concerned about her ecosystem and reporting to the UN Conventions related to the environment. While comparing Tripura (state scoring low in EGI) and Mauritania, we can infer that Tripura is more concerned about female participation while Mauritania is more interested in Female Literacy and ownership rights. State reports of Tripura, or be it any northeastern state is negligible (except Assam). Comparing Chhattisgarh and Saudi Arabia is fascinating as they score the same in terms of EGI but are two extreme cases when its categories decomposed. Chhattisgarh scored average in all the six categories while Saudi Arabia reports practically nothing for open public access to information, does not believe in female political or work participation but wants to lead a harmonious life with all basic amenities. Haryana and Cameroon want to lead a life with access to all essential amenities, and to do that, Cameroon is aware of the significant role the ecosystem play, whereas Haryana does not. Female labor force participation is also far better in Cameroon than in Haryana.

As cited in the IUCN's Environment and Gender Index 2013 Pilot Report, that income is not a factor affecting EGI. Given the fact that 72 countries from all income groups (according to World Bank classification) have been associated with GDP per capita and thus the relation has been not good, whereas their association with Gross National Happiness is good inferring that apart from economic factors, social, cultural, political and psychological factors are also important for EGI's performance. But as only the lower-middle-income countries are considered in this paper, the observations are quite the opposite. Also, Crude Birth Rate falls for countries with higher EGI score. Incidence of sexual violence does not affect EGI on a country level as there is a considerable variation in the perspective of Gender Equality and Gender rights from country to country.

While exploring factors affecting EGI of the states of India, NSDPPC is not much related to EGI's performance. This observation gives justice to the observation made in the EGI report by IUCN as the states of India are compared with both developed and developing countries worldwide. Also, higher performance in EGI does not necessarily mean lower Crude Birth Rate in terms of states of India as various factors are underlying, out of which religious factors are considered most prominent. The most exciting observation lies in the association of the percentage of women suffering from sexual violence. When analysis was 
performed countrywide, the relation was little, but when associated with states of India, the incidence of inverse relation is good. With the higher score in EGI, the incidence of sexual violence becomes low.

Since income is an essential factor affecting EGI of the 20 lower middle-income group of countries taken into consideration, and GDP Per Capita being one of the indicators of these indices (except EPI), the relationship between them and EGI is positive. Also, the countries being homogeneous in nature on a general level, the economic development parameters of all the indices go hand in hand (UNDP, 2010; Foncha \& Ewule, 2020). This interpretation can explain why the EPI shows a moderate relationship with these countries regarding gender equality for the environment. The countries still need to work on preserving their ecosystem and natural resources. On the contrary, the India, being truly called the land of diverse culture, needs all economic, social, cultural, political development to develop on a whole (WEDO Online Library, 2011). This explains why all the indices are not showing positive relation with the EGI score of all the states. The states also show a trend of cluster formation with Kerala and Bihar mostly outlying away, denoting the extremities in terms of the indicators, which includes socio-economic-cultural and political dimensions. Thus India, performing average in EGI, its states performing average (scores from 0.4 to 0.6 approximately), her government needs to inculcate accountability and transparency in terms of her governance and implementation of agreements both international and national. Also, the government needs to improve the country's sex-disaggregated data collection on the indicators discussed, including the variables listed in the EGI Framework and other variables which are compared with EGI and could be a part of the framework itself. On a whole, sustainable development is the root of development and without taking environmental parameters into account, a country with all its states individually cannot develop.

\section{Conclusion}

It is quite amusing to see Indian situation for gender equality and environmental sustainability. India portrays clearly good governance, but fails to bring good livelihood to her citizens, especially women, as they are sometimes denied their basic rights, discriminated when it comes to participation, be it political or of any other kind, denied property rights (note: dowry deaths) and are married off early before they even wish to attain basic education at least. In all these circumstances, the lack of decision making power is acting as an undercurrent.

\section{Conflicts of Interest}

The authors declare no conflicts of interest regarding the publication of this paper.

\section{References}

Agarwal, B. (1992). The Gender and Environment Debate: Lessons from India. Feminist 
Studies, 18, 119-158. https://doi.org/10.2307/3178217

Central Statistical Office (2012). Women and Men in India 2011. 13th Issue, Central Statistical Organization, Ministry of Statistics and Program Implementation, Government of India, Government Press.

FAO (2005). Introducing the African Gender and Development Index. In The African Commission on Agricultural Statistics (AFCAS) Meeting. FAO.

http://www.fao.org/ES/ESS/meetings/download/afcas2005/papers/AFCAS $05 \quad 7 \quad 2$ b.p df

Foncha, J., \& Ewule, D. (2020). Community Forest Management: A Strategy for Rehabilitation, Conservation and Livelihood Sustainability: The Case of Mount Oku, Cameroon. Journal of Geoscience and Environment Protection, 8, 1-14. https://doi.org/10.4236/gep.2020.82001

Hayson, L. (2014). The Environment and Gender Index: Ranking Gender Accountability by Government in Climate Change Policies. University of South Africa Press.

Helliwell, J. F., Layard, R., \& Sachs, J. (2014). World Happiness Report 2013. UN Sustainable Development Solutions Network, Oxford University Press.

Institute of Applied Manpower Research (2012). Indian Human Development Report 2011: Towards Social Inclusion. Planning Commission, Oxford University Press.

Irish Aid (2006). Environment and Gender Equality. Key Sheet 13, Department of Foreign Affairs.

IUCN (2013a). The Environment and Gender Index (EGI) 2013 Pilot. IUCN.

IUCN (2013b). Women in Environmental Decision Making in the Philippines: An Environmental and Gender Index (EGI) Country Case Country. IUCN.

Kakashel, K. (2012). Gender and State Climate Change Action Plans in India. Climate and Development Knowledge Network.

http://cdkn.org/project/gender-and-state-climate-change-action-plans-in-india

Ministry of Women and Child Development (2009). Gendering Human Development Indices: Recasting the Gender Empowerment Measure for India, Ministry of Women and Child Development, UNDP.

National Institute of Public Cooperation and Child Development (NIPCCD) (2010). Statistics on Women in India 2010. National Institute of Public Administration, Government Press.

Phillips, N. (2014). Crime and Safety in the World. Penguin Publications.

Rao, H., \& Dr, K. (2012). Rural Development Statistics 2011-12. National Institute of Rural Development, Ministry of Rural Development, Government of India, Hyderabad.

Rustagi, P. (2004). Significance of Gender-Related Development Indicators: An Analysis of Indian States. Indian Journal of Gender Studies, 3, 32-37.

https://doi.org/10.1177/097152150401100303

UNDP (2010). The Real Wealth of Nations: Pathway to Human Development: Human Development Report 2010. Oxford University Press.

WEDO Online Library (2011). Environment and Gender Equality: The Keys to Achieving Millennium Development Goals. WEDO.

http://www.wedo.org/library/environment-and-gender-equality-the-keys-to-achievingmillennium-development-goals

Young, T. (2013, October). World's First Environment and Gender Index. Borgen Magazine.

http://www.borgenmagazine.com/worlds-first-environment-and-gender-index 